\title{
The 19 kDa Mycobacterium tuberculosis Lipoprotein (LpqH) Induces Macrophage Apoptosis through Extrinsic and Intrinsic Pathways: A Role for the Mitochondrial Apoptosis-Inducing Factor
}

\author{
Alejandro Sánchez, Patricia Espinosa, Teresa García, and Raúl Mancilla \\ Departamento de Inmunología, Instituto de Investigaciones Biomédicas, Universidad Nacional Autónoma de México, \\ Circuito Escolar S/N, Ciudad Universitaria, 04510 México, DF, Mexico \\ Correspondence should be addressed to Raúl Mancilla, mancilla@biomedicas.unam.mx
}

Received 17 September 2012; Revised 7 November 2012; Accepted 20 November 2012

Academic Editor: Maciej Cedzynski

Copyright ( 2012 Alejandro Sánchez et al. This is an open access article distributed under the Creative Commons Attribution License, which permits unrestricted use, distribution, and reproduction in any medium, provided the original work is properly cited.

We describe the association of caspase-dependent and caspase-independent mechanisms in macrophage apoptosis induced by LpqH, a $19 \mathrm{kDa}$ Mycobacterium tuberculosis lipoprotein. LpqH triggered TLR2 activation, with upregulation of death receptors and ligands, which was followed by a death receptor signaling cascade with activation of initiator caspase 8 and executioner caspase 3. In this caspase-mediated phase, mitochondrial factors were involved in loss of mitochondrial transmembrane potential $(\Delta \Psi \mathrm{m})$, release of cytochrome $\mathrm{c}$, and caspase 9 activation. Interestingly, a caspase-independent pathway was also identified; by immunoblot, the mitochondrial apoptosis inducing factor (AIF) was demonstrated in nuclei and cytosol of LpqH-treated macrophages. Confocal microscopy revealed translocation of AIF to the nuclei of the majority of apoptotic cells. These findings emphasize the complex and redundant nature of the macrophage death response to mycobacteria.

\section{Introduction}

Macrophage (MO) apoptosis during Mycobacterium tuberculosis (Mtb) infection has focused much attention on its possible role in disease pathogenesis. A number of findings support this view; it has been shown that virulent mycobacterial strains are less apoptogenic than their attenuated counterparts [1] and MO proapoptotic genes are downregulated by virulent strains while the opposite occurs with avirulent mycobacteria [2]. In contrast with latent infection, in active TB patients the expression of genes that promote apoptosis is diminished [3]. These data and the identification of genes that inhibit $\mathrm{MO}$ apoptosis in some Mtb mutants [4] have added further support to the view that the ability of Mtb to prevent the apoptotic death of host cells is a virulence trait aimed to preserve its cellular niche. On the other hand, that $\mathrm{MO}$ apoptosis represents an innate immune response of the host is suggested by decreased viability of bacilli in apoptotic MO [5-7]. There is also evidence that dendritic cells that have ingested apoptotic MO infected by $\mathrm{Mtb}$ can activate $\mathrm{T}$ cells through a process known as crosspriming which results in the activation of CD8+ T cells $[7,8]$. It is also of interest the identification of Mtb proapoptotic mutants that induce higher $\mathrm{T}$ cell immunity which favors the control of infection [9].

Knowledge about the mechanisms involved in the death of mycobacteria-infected MOs has greatly increased during the last decade. Initially, it was characterized as extrinsic type, caspase-dependent apoptosis with TNF- $\alpha$ activation $[10,11]$. More recent studies have come to show that MO apoptosis in mycobacterial infection is a complex and variegated process. Some reports document the participation of the intrinsic or mitochondrial pathway. Infection with attenuated Mtb strains results in mitochondrial outer membrane permeability with release of cytochrome $\mathrm{c}$ and activation of caspase $9[12,13]$. Recently, the endoplasmic reticulum 
stress and lysosome pathways have been implicated in macrophage apoptosis provoked by mycobacteria [14]. It has been also reported that host cell death might show features of necrosis particularly with increased bacillary loads [15]. These observations could suggest that mycobacteria instead of apoptosis favor necrosis as a mechanism of dissemination and survival.

A few mycobacterial molecules involved in macrophage apoptosis have been identified; among these are $\mathrm{LpqH}$ $[16,17]$, ESAT 6 [11], PE_PGRS33 [18], and PstS-1 [19]. We undertook this study with the aim of knowing better the biochemical pathways used by $\mathrm{LpqH}$ to induce $\mathrm{MO}$ apoptosis, specially to know if mitochondrial factors were involved. $\mathrm{LpqH}$ is interesting for several reasons; it is one of the few mycobacterial proteins, which in addition to acyl groups possess mannose residues [20]. Recently, we demonstrated that LpqH behaves as an adhesin that interacts with the mannose receptor to promote phagocytosis of mycobacteria [21]. LpqH induces T cell-mediated immunity, although it might also behave as a TLR2 agonist that downregulates antigen presentation to T cells [22].

From the above data, it is clear that the death of mycobacteria-infected MOs is a relevant, mechanistically complex phenomenon. To this complexity contribute findings we present herein. We show that in addition to TLR2 dependent, death receptor-mediated apoptosis, LpqH triggers an intrinsic or mitochondrial pathway, with the participation of cytochrome $\mathrm{c}$ and the apoptosis-inducing mitochondrial factor (AIF), a previously unrecognized mechanism of MO cell death induced by Mtb.

\section{Materials and Methods}

2.1. Materials. Murine monoclonal antibodies (mAbs) to human TNF- $\alpha$ (clone 28401) and human TNFR1 and human TNFR2 (clone 22221) were purchased from R\&D Systems (Minneapolis, MN, USA); mAbs to human Fas (clone ZB4) and FasL (clone B-R17), caspase 8, caspase 9, and caspase 3 were purchased from Upstate Cell Signaling (Lake Placid, NY, USA); mAb to human TLR2 (clone TL2.1) were from eBioscience (San Diego, CA, USA) and TLR4 (clone HTA-125) was obtained from Santa Cruz Biotechnology (Santa Cruz, CA, USA). A mouse monoclonal antibody to the human-apoptosis inducing factor (AIF) was obtained from Santa Cruz Biotechnology (clone E20). A goat polyclonal antibody to human cytochrome $\mathrm{c}$ was purchased from Santa Cruz Biotechnology (clone C-20). Horseradish peroxidase-conjugated control isotype antibodies to goat IgG and to mouse IgG were from Dako (Carpinteria, CA, USA). A cell-death detection enzyme-linked immunosorbent assay (ELISA) Plus was obtained from Roche Diagnostics (Penzberg, Germany). A specific cell-permeable pancaspase inhibitor Z-VAD-FMK was obtained from BD Pharmingen (San Diego, CA, USA). Ficoll-Hypaque was from Amersham Biosciences (Piscataway, NJ, USA); polymyxin B, Ponceau red, and dimethyl sulfoxide (DMSO) were from Sigma-Aldrich (St. Louis, MO, USA). A subcellular protein fractionation kit fractionation was obtained from Thermo
Scientific (Rockford, IL, USA). The fluorescent lipophilic dye 3,3' dihexyloxacarbocyanine iodide (DiOC6) was purchased from Molecular Probes (Eugene, OR, USA).

2.2. Mycobacteria and Isolation of LpqH. A native Mycobacterium smegmatis strain (mc2155) and its counterpart transformed by electroporation with the plasmid p16R1 containing a $1.8 \mathrm{~kb}$ SmaI fragment that includes the structural gene encoding the LpqH lipoprotein were kindly donated by Y. Zhang (MRC Tuberculosis and Related Infections Unit, Hammersmith Hospital, London, UK). M. smegmatis strains were grown for 4-5 days in Middlebrook 7H9 medium (BBL, Becton-Dickinson, Cockeysville, MD, USA) supplemented with $2 \%$ glucose and hygromycin B $(50 \mathrm{mg} / \mathrm{mL})$. Bacteria were harvested by centrifugation and washed with ice-cold sodium phosphate buffer $(10 \mathrm{mM} / \mathrm{L})$. To isolate LpqH, cellwall fractions were obtained by sonication of bacteria at $20 \mathrm{KHz}$ in iced water (five cycles of $5 \mathrm{~min}$ each). Proteins were resolved by $12 \%$ or $15 \%$ sodium dodecyl sulfate polyacrylamide gel electrophoresis (SDS-PAGE) and transferred to nitrocellulose. The $19 \mathrm{kDa} \mathrm{LpqH}$ band was identified by immunoblot with mAb IT-19, which was donated by TB Vaccines Testing and Research Materials Contract, Colorado State University. In order to obtain LpqH to induce apoptosis, cell wall fractions were obtained by sonication and $30 \mu \mathrm{g}$ protein was mixed with an equal volume of reducing sample buffer $(0.05 \mathrm{mM}$ EDTA, $0.1 \%$ SDS, $1 \%$ glycerol, $10 \% 2$ mercaptoethanol, and $0.5 \mathrm{mM} / \mathrm{mL}$ Tris- $\mathrm{HCl} \mathrm{pH} 6.8$ ), heated for $5 \mathrm{~min}$ at $95^{\circ} \mathrm{C}$, and loaded into $1 \mu \mathrm{L} 1.5 \mathrm{~mm}$ slot $20 \mathrm{~cm}$ long gels. After electrophoresis, proteins were transferred to nitrocellulose sheets and stained with Ponceau red to identify the $19 \mathrm{kDa}$ band; the identity of this band was confirmed in parallel blots with the IT-19 mAb. Thereafter, the band was excised, solubilized in DMSO, and precipitated with an equal volume of carbonate/bicarbonate sodium buffer (0.05 M, pH 9.6). The pellet was rinsed three times with ice-cold PBS and aliquots were stored at $20^{\circ} \mathrm{C}$. Protein concentration was determined with the Lowry method using BSA as standard. Native M. smegmatis cell wall fractions were electron-transferred to nitrocellulose membranes and a 19$\mathrm{kDa}$ strip was excised and processed as above to be used in apoptosis assays as a control. Western blots with the IT-19 $\mathrm{mAb}$ failed to demonstrate $\mathrm{LpqH}$ in cell walls of native $M$. smegmatis bacilli (not shown).

\subsection{Apoptosis Assays to Determine Capacity of LpqH to} Kill Human Monocyte-Derived Macrophages. Blood samples were obtained from healthy donors and mononuclear cells were separated by the Ficoll-Hypaque gradient centrifugation. Cells were cultured in Petri dishes (Corning Inc., Corning, NY, USA), in RPMI-1640 supplemented with $20 \%$ fetal bovine serum, $5 \mathrm{mM} / \mathrm{L}$ L-glutamine, and $5 \mu \mathrm{g} / \mathrm{mL}$ penicillin-streptomycin, at $37^{\circ} \mathrm{C}$ in a humidified $5 \% \mathrm{CO}_{2}$ atmosphere. After overnight incubation at $37^{\circ} \mathrm{C}$, adherent cells were cultured with $10 \%$ fetal bovine serum. This step is considered necessary to get rid of nonadherent cells, death cells, and nonmacrophagic cells. At 7 days of culture and after treatment with RPMI-1640 containing EDTA ( $5 \mathrm{mM} / \mathrm{L})$, at 
$4^{\circ} \mathrm{C}$ for $10 \mathrm{~min}$, activated macrophages were gently detached with a cell scraper. After rinsing, cells $\left(5 \times 10^{5}\right)$ were placed in 12-well flat-bottom plates (Corning Inc., Corning, NY, USA); at this time, trypan blue exclusion showed $>95 \%$ cell viability. Thereafter, cells were incubated with $0.5,5$, or $50 \mu \mathrm{g}$ of $\mathrm{LpqH}$ for 1 or $24 \mathrm{~h}$ at $37^{\circ} \mathrm{C}$. For control, cells were incubated with $100 \mu \mathrm{g}$ protein present in $19 \mathrm{kDa}$ region of native M. smegmatis cell wall. Apoptosis was measured by ELISA with a cell-death detection kit according to the manufacturer's instructions. Plates were analyzed with an ELISA reader (Bio-Tek Instruments, Winooski, VT, USA).

2.4. Detection of Caspase Activation by Immunoblot and Inhibition Assays with a Pancaspase Inhibitor. Macrophages $\left(2 \times 10^{6}\right)$ were incubated with $5 \mu \mathrm{g} \mathrm{LpqH}$ for $1 \mathrm{~h}$. Thereafter, whole cell extracts were obtained after cells were lysed and vortexed with $100 \mu \mathrm{L}$ radioimmunoprecipitation assay buffer (50 mM Tris-HCl, pH 7.0, 50 mM NaCl, 1\% NP40, $0.5 \%$ sodium deoxycholate, and $0.1 \%$ SDS) and let stand for $20 \mathrm{~min}$ at $4^{\circ} \mathrm{C}$. Cell lysates were centrifuged $(34025.6 \mathrm{~g}$ for $15 \mathrm{~min}$ at $4^{\circ} \mathrm{C}$ ) and the supernatant was obtained; $35 \mu \mathrm{g}$ protein were resolved by $17.5 \%$ SDS-PAGE and transferred to polyvinylidene difluoride (PVDF) membranes; after blocking with 5\% nonfat milk in PBS, membranes were incubated with mAbs to caspase 8, 9, and 3 (dilution 1/1000), overnight, at $4^{\circ} \mathrm{C}$. After rinsing, membranes were incubated with horseradish peroxidase-conjugated secondary antibodies (dilution 1/1000), for $1 \mathrm{~h}$, at room temperature. Reactive bands were visualized by chemiluminescence with SuperSignal West Dura kit (Pierce, Rockford, IL, USA). Inhibition of caspase activity was measured as follows. Monocyte-derived macrophages $\left(1 \times 10^{6}\right)$ were preincubated for $30 \mathrm{~min}$ at $37^{\circ} \mathrm{C}$ with $20 \mu \mathrm{M}$ of the pancaspase inhibitor Z-VAD-FMK. After rinsing, cells were incubated with $5 \mu \mathrm{g}$ $\mathrm{LpqH}$ for 1 or $24 \mathrm{~h}$ at $37^{\circ} \mathrm{C}$. Apoptosis was measured by ELISA as described before.

2.5. Quantitation of Death Receptors TNFR1, TNFR2, and Fas and Their Ligands TNF- $\alpha$ and Fas. To quantitate TNF$\alpha$ production, $5 \times 10^{5}$ cells were incubated for $1 \mathrm{~h}$ with $5 \mu \mathrm{g}$ LpqH or with $100 \mu \mathrm{g}$ protein present in native M. smegmatis $19 \mathrm{kDa}$ strips. Supernatants were collected by centrifugation at $390.6 \mathrm{~g}$ for $5 \mathrm{~min}$ and TNF- $\alpha$ was measured after $0,5,15$, 30,45 , and 60 min treatment, with an ELISA kit according to the manufacturer's instructions (Assay Designs, Inc, Ann Arbor, MI, USA). Duplicate samples were analyzed with an ELISA reader and compared with a standard curve. The expression of death receptors and their ligands was determined by a cell-surface ELISA method. After induction of apoptosis by incubation of cells $\left(5 \times 10^{5}\right)$ with $5 \mu \mathrm{g} \mathrm{LpqH}$ for $1 \mathrm{~h}$ at $37^{\circ} \mathrm{C}$, cells were rinsed with PBS containing $1 \%$ fetal bovine serum and $0.1 \% \mathrm{NaN}_{3}$. The mouse mAb used were: to human TNFR1 $(1 \mu \mathrm{g} / \mathrm{mL}$, dilution $1 / 100)$, human TNFR2 $(2 \mu \mathrm{g} / \mathrm{mL}$, dilution $1 / 100)$, human Fas $(1 \mu \mathrm{g} / \mathrm{mL}$, dilution $1: 100)$, and human FasL $(0.5 \mu \mathrm{g} / \mathrm{mL}$, dilution $1 / 100)$. After apoptosis induction, cells were extensively rinsed and incubated for $1 \mathrm{~h}$ with each of the above antibodies. For control, irrelevant isotype antibodies were used. Thereafter, cells were rinsed with PBS and incubated for $1 \mathrm{~h}$ with peroxidaselabeled goat or mouse anti-IgG antibodies diluted 1/1000. Finally, $100 \mu$ Lof ABTS solution were added to the cells. Optical densities at $405 \mathrm{~nm}$ was read by an ELISA reader (Asys Expert Plus, HyTech, Austria).

2.6. Inhibition Assays to Assess the Role of TLR2 and TLR4 and of Death Receptors and Their Ligands in LpqH-Induced Macrophage Apoptosis. Cells were preincubated for $30 \mathrm{~min}$ at $37^{\circ} \mathrm{C}$ with blocking mAb to human TNF- $\alpha(1 \mu \mathrm{g} / \mathrm{mL})$, human TNFR1 $(5 \mu \mathrm{g} / \mathrm{mL})$, or human TNFR2 $(1.5 \mu \mathrm{g} / \mathrm{mL})$. Inhibition assays were also performed with blocking $\mathrm{mAbs}$ to human Fas $(500 \mathrm{ng} / \mathrm{mL})$ and to human FasL $(32 \mathrm{ng} / \mathrm{mL})$. To study the role of Toll-like receptors in the induction of apoptosis, cells were preincubated with blocking mAbs $(20 \mu \mathrm{g} / \mathrm{mL})$ to TLR2 and to TLR4. Control isotype antibodies were used. After preincubation with antibodies, without rinsing, $5 \mu \mathrm{g}$ of $\mathrm{LpqH}$ was added to the cells to induce apoptosis which was analyzed by ELISA as above.

2.7. Evaluation of Mitochondrial Membrane Potential by Flow Cytometry with DiOC6. In order to analyze the participation of the mitochondria, we analyze the mitochondrial membrane potential by flow cytometry using the cationic lipophilic fluorochrome 3,3' -dihexyloxacarbocyanine iodide (DiOC6). Loss in DiOC6 staining indicates disruption of the mitochondrial inner transmembrane potential $(\Delta \Psi \mathrm{m})$ which is often associated with apoptosis [23]. Cells $\left(1 \times 10^{6} / \mathrm{mL}\right)$ were incubated with $5 \mu \mathrm{g} \mathrm{LpqH}$ for 1 and $24 \mathrm{~h}$ and washed three times with PBS, and 40 nM DIOC6 was added to pellet for $30 \mathrm{~min}$ at $37^{\circ} \mathrm{C}$ in the dark. DiOC6 was prepared from a $40 \mathrm{mM}$ stock solution in DMSO which was diluted with PBS, $\mathrm{pH} 7.4$, to a $400 \mathrm{nM}$ working solution. Cells were diluted with PBS to a final volume of $1 \mathrm{~mL}$ and analyzed by flow cytometry.

2.8. Subcellular Fractionation and Immunoblot to Determine Mitochondrial Release of Cytochrome $c$ and AIF. MOs treated with $5 \mu \mathrm{g} \mathrm{LpqH}$ for 1 and $24 \mathrm{~h}$ were subjected to a subcellular fractionation procedure. Cytosolic and nuclear proteins were extracted using a subcellular protein fractionation kit, following protocols from the manufacturer (ThermoScientific). Protein concentrations were measured with the Bio-Rad DC protein assay (Hercules, CA, USA). Proteins $(50 \mu \mathrm{g})$ were separated by SDS-PAGE in $7.5 \%$ polyacrylamide gels and transferred to nitrocellulose membranes. After blocking in 5\% non-fat dried milk at room temperature for $1 \mathrm{~h}$, membranes were incubated overnight with a mouse $\mathrm{mAb}$ to human AIF diluted $1 / 200$ in TBS with BSA $5 \%$ and $0.01 \%$ Tween 20 ; a secondary anti-mouse IgG peroxidaselabeled antibody was used. Different strips were incubated with a polyclonal goat antibody to human cytochrome c, diluted $1 / 200$ in PBS Tween 20, 0.01\%, overnight. A secondary antibody to goat IgG labeled with peroxidase was used diluted 1/1000. The SuperSignal West Femto Maximum Sensitivity Substrate chemiluminescence kit was used to reveal reactive bands. 
2.9. Immunofluorescence to Detect AIF in Nuclei of Macrophages Treated with LpqH. Translocation of AIF from mitochondria to the nucleus during apoptosis was analyzed by immunofluorescence of untreated cells or cells treated with LpqH for 1 and $24 \mathrm{~h}$. Cells were rinsed with PBS and fixed in a solution of $1 \%$ paraformaldehyde in PBS. Cell suspensions were placed by cytospin onto glass slides previously treated with poly-L-lysine. Slides were washed once with PBS and a drop a $0.05 \%$ saponin solution in PBS was added for $5 \mathrm{~min}$, rinsed with PBS, and incubated for $1 \mathrm{~h}$ with the anti-AIF $\mathrm{mAb}$, diluted $1 / 200$, at room temperature in a humidified chamber; slides were rinsed with PBS and incubated for 45 min with a 1/500 dilution of an anti-mouse IgG antibody labeled with CY5. Slides were mounted with ProLong Gold antifade with DAPI (Molecular Probes). Cells were examined with an Olympus BX51 microscope and with a laser scanning confocal microscope LSM 5 Pascal Zeiss with Software 2.8.

\section{Statistical Analysis}

To compare individual experiments, optical density (OD) of cells that were not exposed to the apoptogenic protein was set to 1 . All other OD values within an experiment were divided by the OD of untreated control cells to provide a relative apoptosis value in arbitrary units. Data obtained from independent experiments are presented as the mean $\pm \mathrm{SE}$, and the differences between conditions were analyzed using Student's $t$-test and Student's paired $t$-test. Differences at $P<0.05$ and $P<0.01$ were considered significant.

\section{Results}

4.1. In the Apoptotic Death of Human Macrophages Participate Caspase-Dependent Mechanisms. Studies in our laboratory with whole bacilli or cell walls showed that a transformed M. smegmatis strain that overexpresses the LpqH lipoprotein induces high levels of apoptosis in the human monocytic THP-1 cell line (data not shown). To investigate whether the transfected $\mathrm{LpqH}$ was responsible, we incubated human $\mathrm{MO}$ obtained from peripheral blood from healthy individuals with $0.5,5$, or $50 \mu \mathrm{g}$ isolated $\mathrm{LpqH}$. As a control, MOs were incubated with $100 \mu \mathrm{g}$ protein present in $19-\mathrm{kDa}$ nitrocellulose strips of native $M$. smegmatis which does not contain LpqH as shown by immunoblot (not shown). A nucleosome ELISA method revealed that $\mathrm{LpqH}$ induces apoptosis at high rates, significantly higher than those induced by native $M$. smegmatis proteins (Figure $1(\mathrm{a}) ; P<$ 0.05). Assays using polymyxin B ruled out LPS participation (data not shown). To investigate the caspase dependence of apoptosis, protein extracts from apoptotic cells were separated by SDS-PAGE, transferred to PVDF sheets, and incubated with $\mathrm{mAb}$ to detect activated forms of caspases. Results revealed procaspases as well as bands corresponding to the activated isoforms of caspases 8, 3, and 9 (Figure 1(b)).

4.2. Mycobacterium tuberculosis LpqH Activates a Proapoptotic Role in TLR2. It is well established that TLR2 and TLR4 may behave as cell death receptors and that activation of
TLR2 by bacterial lipoproteins may induce apoptosis [24, 25]. To investigate if this occurred in LpqH-treated MO, we carried out inhibition assays with blocking antibodies to these receptors. In cells preincubated with a mAb to human TLR2 and then exposed to $5 \mu \mathrm{g} \mathrm{LpqH}$, there was a significant reduction in apoptosis levels (Figure $2 ; P<$ $0.01)$. This finding indicates that apoptosis is induced by the interaction of TLR2 with motifs present in the mycobacterial lipoprotein. Apoptosis of cells that were preincubated with a mAb to human TLR4 was not modified, a finding in keeping with the fact that this receptor is activated preferentially by LPS motifs and not by lipoproteins [25]. These findings suggest that TLR2 activation acts upstream in the signaling cascade leading to LpqH-induced MO apoptotic death.

4.3. Fas and FasL Participate in Macrophage Apoptosis Triggered by $L p q H$. Information on the role of FasL in macrophage apoptosis induced by mycobacteria is scanty [5]; therefore, we examined the role of FasL and its receptor in LpqH-induced apoptosis. A cell surface ELISA analysis showed that in cells incubated with LpqH, Fas expression was similar to that of untreated cells. In contrast, membrane-bound FasL was significantly increased $(P<$ 0.01 ; Figure $3(\mathrm{a}))$. This finding is of note because usually FasL is released efficiently from the cell-surface by metalloproteinases [26]. To know if Fas or FasL had a role in apoptosis, inhibition assays were carried out. When MOs were preincubated with blocking mAb against Fas and FasL, the apoptosis levels were significantly decreased (Figure 3(b); $P<0.01 ; P<0.05)$.

4.4. Involvement of TNF- $\alpha$ and Its Receptors in Macrophage Apoptosis. TNF- $\alpha$ production during LpqH-induced $\mathrm{MO}$ apoptosis was measured by an ELISA method in the cultured medium of cells incubated with $5 \mu \mathrm{g} \mathrm{LpqH}$ for $15,30,45$, and $60 \mathrm{~min}$. Increased time-dependent TNF- $\alpha$ values were observed, which were maximal at $60 \mathrm{~min}$ (Figure 4(a)). At this time, cells treated with LpqH released TNF- $\alpha$ in amounts significantly higher than those of cells incubated with $100 \mu \mathrm{g}$ native $M$. smegmatis proteins present in the $19-\mathrm{kDa}$ region (Figure $4(\mathrm{~b}) ; P<0.05)$. In view of the importance of TNFR1 and TNFR2 in the cytotoxic capacity of TNF- $\alpha$ [27], their expression was analyzed by a cell surface ELISA procedure. Both receptors were overexpressed after treatment with $5 \mu \mathrm{g}$ LpqH (Figure 4(c); $P<0.01$ ). To know whether TNF- $\alpha$ and death receptors upregulation was related to the induction of apoptosis, inhibition assays with blocking antibodies were carried out. It was observed that mAbs to TNF- $\alpha(P<0.05)$, TNFR1 $(P<0.01)$, and TNFR2 $(P<0.01)$ decreased apoptosis significantly (Figure $4(\mathrm{~d})$ ). The latter observation is interesting because TNFR2 is a receptor devoid of celldeath domains $[27,28]$. By cell surface ELISA no differences were found in TNF- $\alpha$ membrane expression between LpqHtreated and untreated cells (not shown). No effect was observed with an isotype control.

4.5. Participation of Mitochondrial Factors in LpqH-Induced Apoptosis. Immunoblot analysis of cells driven apoptotic by 


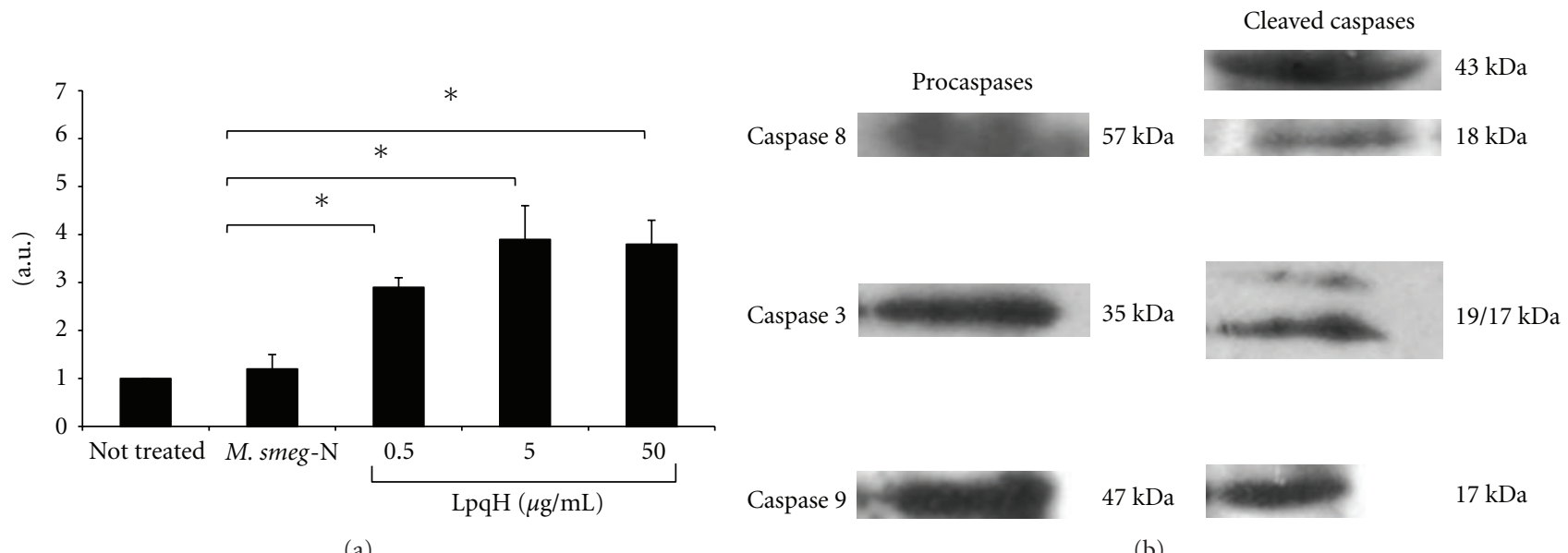

(a)

(b)

FIGURE 1: Mycobacterium tuberculosis LpqH lipoprotein induces caspase-dependent macrophage apoptosis. (a) Peripheral blood monocytederived human macrophages were incubated for $1 \mathrm{~h}$ with $\mathrm{LpqH}$. As a control, cells were incubated with $100 \mu \mathrm{g}$ protein present in $19-\mathrm{kDa}$ nitrocellulose strips of native M. smegmatis (M. smeg- $N$ ), which as seen by immunoblot do not contain LpqH (not shown). Apoptosis was measured with a nucleosome ELISA kit. Apoptosis is expressed as the mean \pm SE arbitrary units (a.u.)of four independent experiments. Statistically significant differences are indicated; ${ }^{*} P<0.05$. (b) To determine the role of caspases, whole-cell protein extracts of MO made apoptotic by incubation with $5 \mu \mathrm{g}$ LpqH were separated by SDS-PAGE and immunoblot analysis was performed with antibodies to caspases 8,3 , and 9. Procaspases and cleaved caspases are shown.

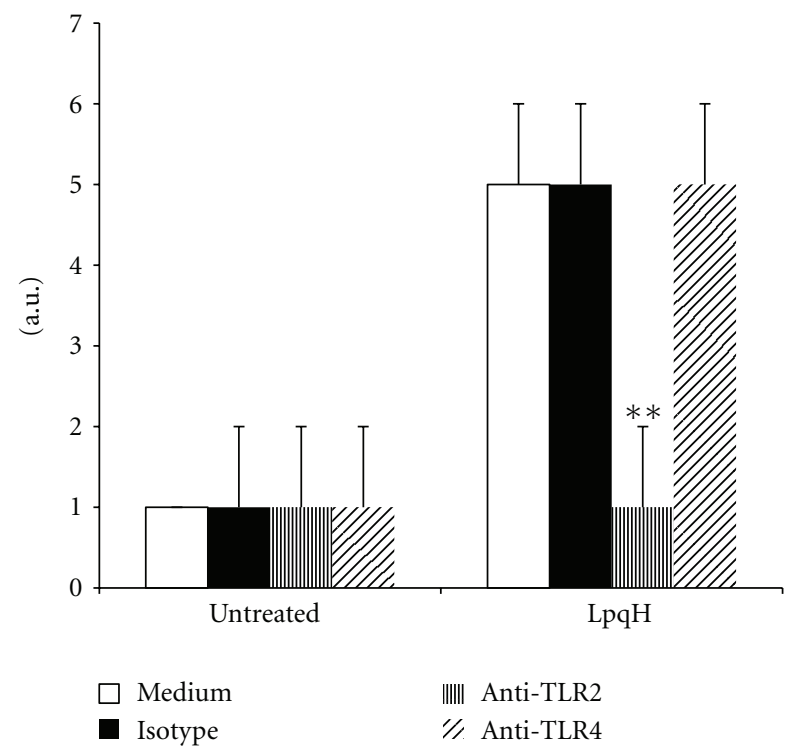

FIGURE 2: LpqH triggers a TLR2 cell death program. To determine a possible role of TLR2 in MO apoptosis, inhibition assays were performed using a specific mAb known by its ability to block TLR2 activation; $0.5 \times 10^{6}$ cells were preincubated with $20 \mu \mathrm{g}$ antibody for $1 \mathrm{~h}$ and then with $5 \mu \mathrm{g} \mathrm{LpqH}$ to induce apoptosis. A similar procedure was used to analyze the participation of TLR4. Apoptosis was analyzed with a nucleosome ELISA kit. Values are given as the mean \pm SE of four independent experiments. Statistically significant differences are indicated; ${ }^{* *} P<0.01$.

LpqH exposure showed activation of caspase 9 (Figure 1(b)) which requires the participation of mitochondrial factors [29]. Activation of caspase 9 requires apoptosome formation which is promoted by cytochrome $\mathrm{c}$ when it is released from the mitochondria [29]. Hence, we obtained subcellular fractions from $\mathrm{MO}$ treated with $\mathrm{LpqH}$ for $24 \mathrm{~h}$ to perform immunoblot analysis. In the cytosol, a mAb antibody specific for human cytochrome $c$ revealed the expected presence of a $15 \mathrm{kDa}$ band (Figure $5(\mathrm{a})$ ). To further asses the role of mitochondria, we tested whether $\mathrm{LpqH}$ caused a loss in mitochondrial transmembrane potential $(\Delta \Psi \mathrm{m})$ using the cationic lipophilic fluorochrome DiOC6 [30, 31]. In this study, fluorescence microscopy of labeled MO displayed the punctate cytoplasmic pattern characteristic of mitochondria labeling, with no discernible plasma membrane labeling (data not shown). In comparison with control cells, in LpqHtreated cells, there was a $27.51 \%$ decrease in DiOC6 labeling (Figure 5(b)), indicating disruption of the mitochondrial inner transmembrane potential $(\Delta \Psi \mathrm{m})$, a change often associated with apoptosis [31].

4.6. Caspase-Independent Mechanisms Are Involved in LpqHInduced Apoptosis: A Role for the Apoptosis-Inducing Factor $(A I F)$. In view of the implication of mitochondrial factors in the induction of caspase-dependent apoptosis, we considered possible that caspase-independent factors could be also involved in $\mathrm{LpqH}$-induced $\mathrm{MO}$ death. Therefore, we carried out assays with the pancaspase inhibitor Z-VADFMK (Figure 6(a)). In cells treated with LpqH for $1 \mathrm{~h}$, there was $49.08 \%$ reduction in apoptosis $(P<0.05)$, while in cells treated with $\mathrm{LpqH}$ for $24 \mathrm{~h}$, apoptosis reduction was of only $19.41 \%(P<0.05)$. This suggested a role for a caspase-independent mechanism. It is well established that after a variety of apoptotic stimuli, AIF is rapidly released from the mitochondria and relocated to the nuclei to induce chromatin condensation and cell death which is unresponsive to caspase inhibitors $[32,33]$. Therefore, we 


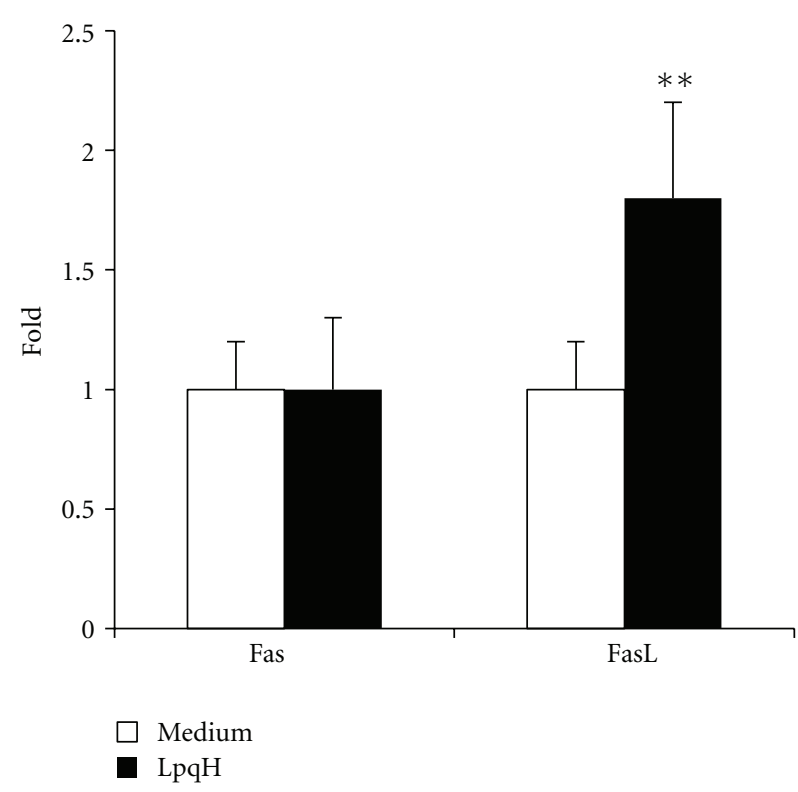

(a)

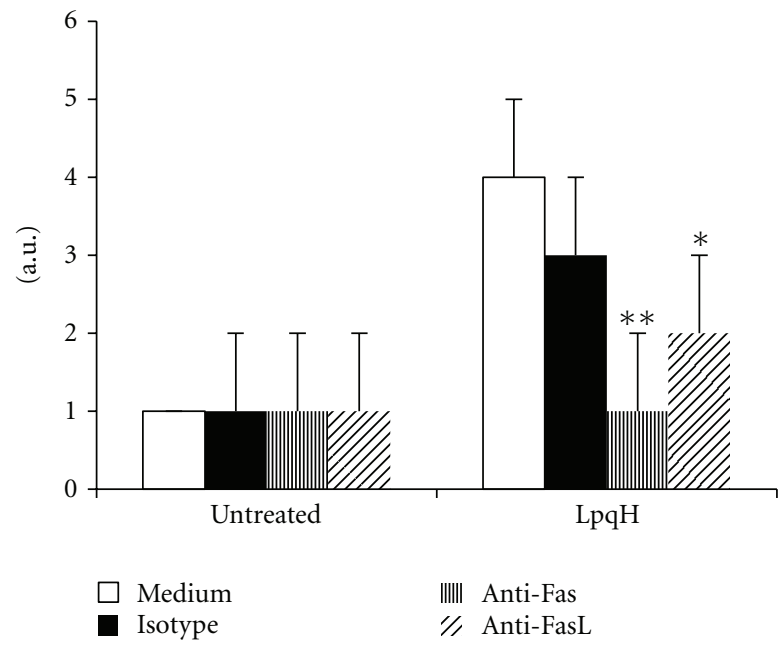

(b)

Figure 3: In the LpqH-induced apoptosis participate Fas/FasL. (a) MOs were incubated for $1 \mathrm{~h}$ with $5 \mu \mathrm{g}$ LpqH and the expression of Fas and FasL was quantitated by a cell surface ELISA method using specific mAb. The relative fold increase over untreated cells (set to 1 ) is shown as the mean $\pm S E$ of four independent experiments; statistically significant differences are indicated; ${ }^{* *} P<0.01$. (b) Inhibition assays to establish the role of Fas and FasL were carried out. MOs were preincubated with neutralizing mAb to Fas and FasL. Thereafter, without rinsing, cells were incubated with $5 \mu \mathrm{g} \mathrm{LpqH}$ for $1 \mathrm{~h}$. The mean $\pm \mathrm{SE}$ apoptosis level of 3 independent experiments is indicated. ${ }^{*} P<0.05$; $* * P<0.01$.

investigated by immunoblot the subcellular distribution of AIF in cells treated with $\mathrm{LpqH}$ for $24 \mathrm{hr}$. In nuclei and cytosol, a doublet band was observed, one of them of $57 \mathrm{kDa}$, a molecular weight that corresponds to activated or truncated AIF (Figure 6(b)); the upper band corresponds to uncleaved AIF $[32,33]$. To confirm these findings, we performed immunofluorescence with a CY5-labeled mAb to AIF; many confocal microscopy photographs taken at the central part of the cell were examined. In cells treated with LpqH for 1 and $24 \mathrm{~h}$, translocation of AIF was seen in many nuclei as magenta fluorescent spots or massive fluorescence (Figure 6(c)); magenta fluorescence results from the colocalization of CY5 (red fluorescence) which labels AIF and DAPI nuclear staining (blue fluorescence). Unaffected or not treated control cells showed AIF emitting CY5 red fluorescence, localized to the cytoplasm, with a punctate pattern characteristic of mitochondrial labeling (Figure 6(c)). Epifluorescence was used to quantitate AIF nuclear translocation in 3 independent experiments; photographs were taken in several randomly chosen fields, and for quantitative analysis at least 500 cells per condition were scored as showing or not AIF in nuclei (Figure 6(d)); similar percentages of cells were positive for AIF at $1(67.7 \%)$ and $24 \mathrm{~h}(59.5 \%)$.

\section{Discussion}

Although the apoptogenic capacity of $\mathrm{LpqH}$ has been reported before $[16,17]$, this study gives new insight about the mechanisms involved. It is shown that both extrinsic and intrinsic mechanisms, including AIF relocation, act together to provoke the apoptotic death of human $\mathrm{MO}$ challenged with LpqH. In the extrinsic or receptor-mediated pathway, a novel observation was the overexpression of membrane-bound FasL, a protein that is cleaved with high efficiency from the cell surface by metalloproteinases [26]. It is interesting that membrane-bound FasL is a considerably more potent inducer of apoptosis than soluble FasL [34]. This property could be relevant in TB since tuberculous granulomas contain numerous macrophages that express surface FasL [35]; this raises the possibility that these FasL armed cells may kill by direct contact Fas-expressing cells within the granuloma. Another new observation was the upregulation not only of TNF- $\alpha$ but also of both TNFR1 and TNFR2 receptors; this increased expression was significant as shown by inhibition assays with blocking $\mathrm{mAb}$ which reduced apoptosis levels significantly. This finding poses the question of how TNFR2 participates in LpqH induced cell death considering that in contrast to TNFR1, TNFR2 lacks a death domain. It has been reported that TNFR2 may participate in apoptosis by inducing endogenous TNF- $\alpha$, depleting antiapoptotic signals, or increasing TNFR1 expression [27, 28].

In this study we found that in the MO death induced by LpqH, TLR2 signals as an upstream activator of the apoptosis cascade. This was demonstrated in inhibition assays with blocking antibodies. Like other bacterial lipoproteins $\mathrm{LpqH}$ is a TLR2 agonist that can either activate cells to produce proinflammatory cytokines [22] or trigger the death of host cells $[16,17]$. The motifs in LpqH that active TLR2 

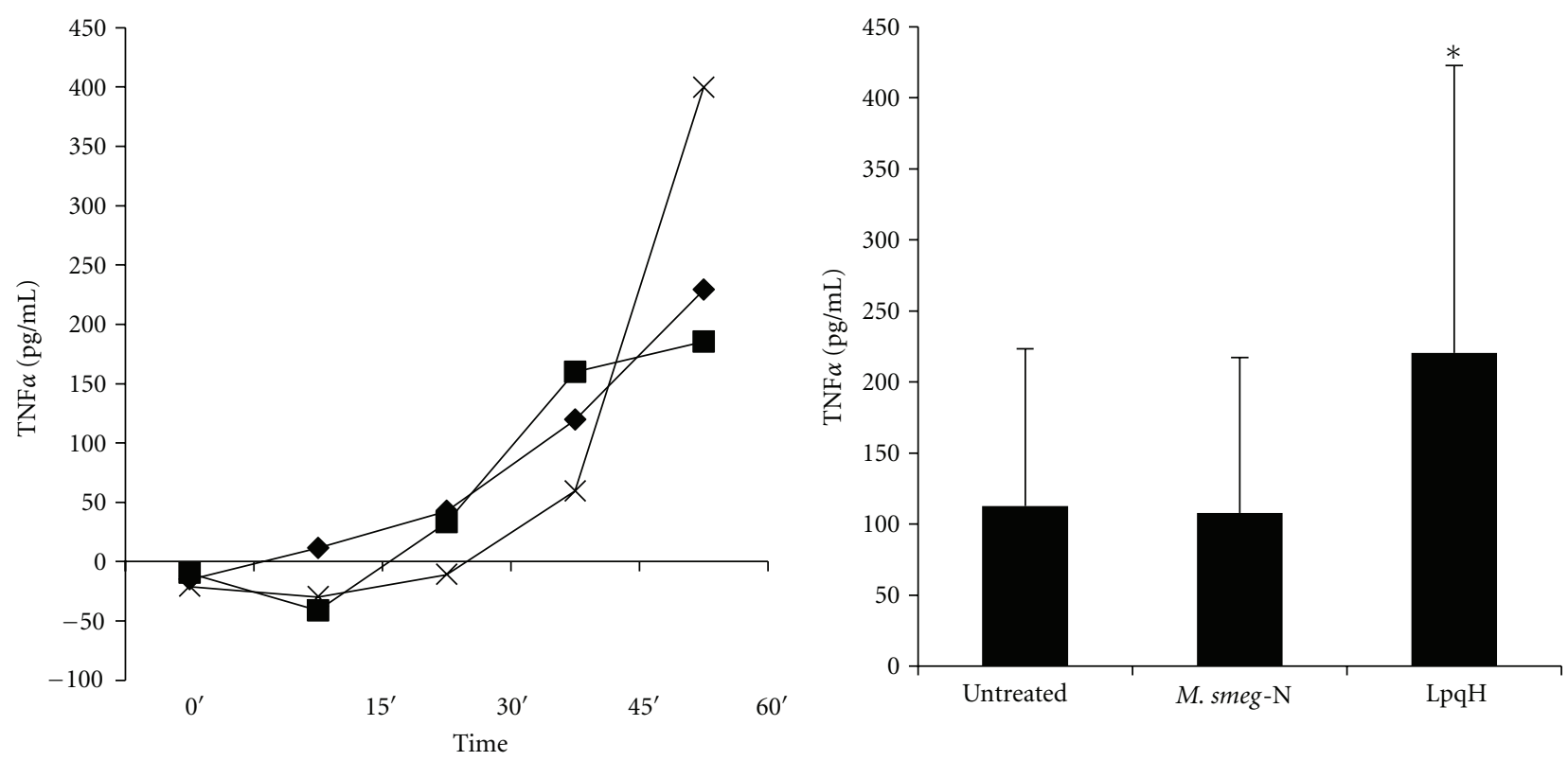

(a)

(b)



(c)

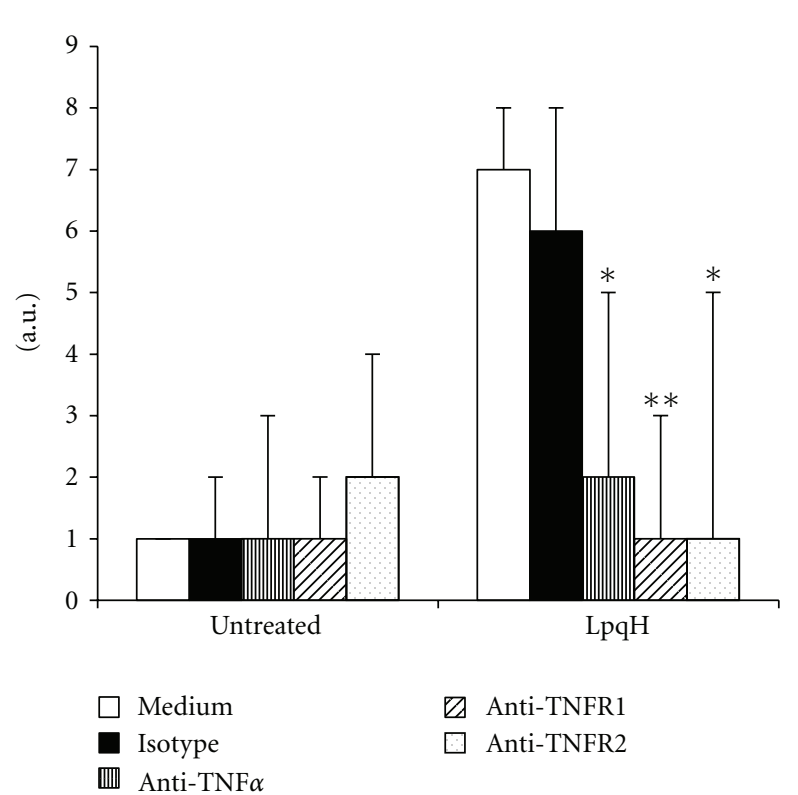

(d)

FIgURE 4: TNF- $\alpha$ and their receptors are upregulated in LpqH-promoted apoptosis. (a) MOs were incubated with $5 \mu \mathrm{g}$ LpqH to induce apoptosis. Control cells were incubated with $100 \mu$ g native M. smegmatis protein (M. smeg-N). At indicated times the culture medium was collected and TNF- $\alpha$ production was quantitated by ELISA. (b) Culture media of apoptotic cells and control cells were collected at 60 min and TNF- $\alpha$ was measured by ELISA. Values are presented as the mean \pm SE of three independent experiments; ${ }^{*} P<0.05$. (c) After $1 \mathrm{~h}$ incubation of cells with $5 \mu \mathrm{g} \mathrm{LpqH}$, the expression of TNFR1 and TNFR2 was measured by cell surface ELISA. The relative fold increase compared with untreated cells (here set to 1 ) is shown as the mean \pm SE of three independent experiments; ${ }^{* *} P<0.01$. (d) MOs were preincubated with neutralizing mAb to human TNF- $\alpha$, TNFR1, and TNFR2. Thereafter, without rinsing, $5 \mu \mathrm{g}$ LpqH was added to cells for $1 \mathrm{~h}$; apoptosis was measured as described in Materials and Methods. Results are given as the mean \pm SE of three independent experiments. Statistically significant differences are indicated; ${ }^{*} P<0.05 ;{ }^{*} P<0.01$. 


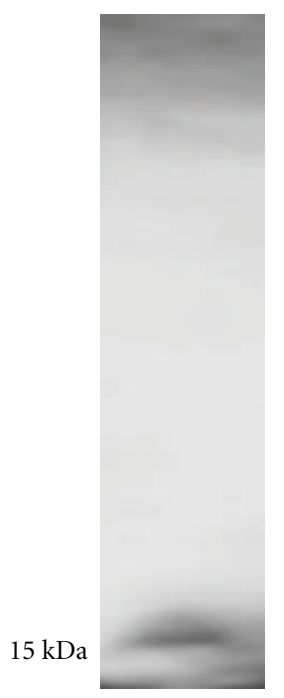

(a)

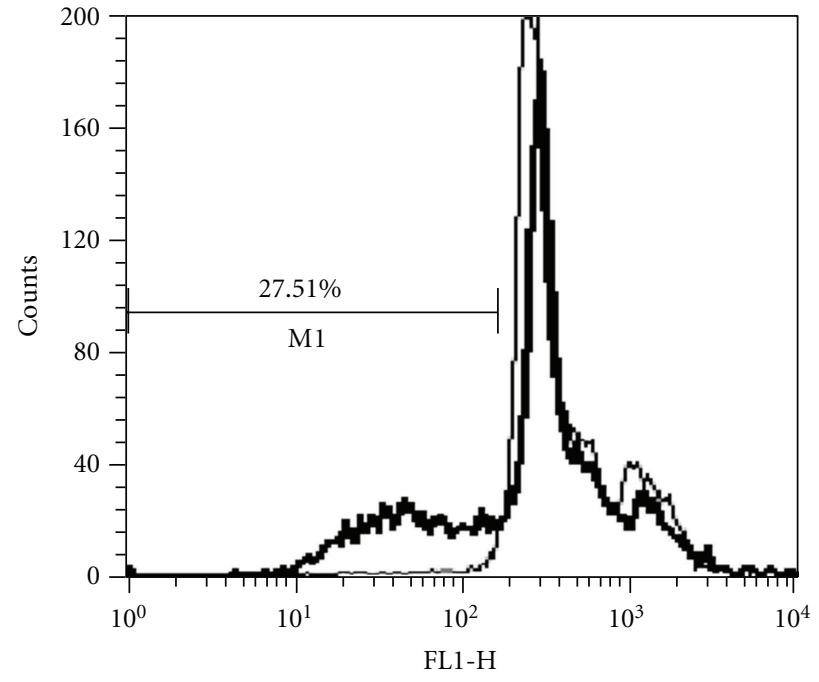

(b)

FIGURE 5: Engagement of mitochondrial factors in the caspase-dependent phase of the death cascade triggered by LpqH. (a) To know if LpqH induces transfer of cytochrome $\mathrm{c}$ from the mitochondria to the cytosol, we perform immunoblot of cytosolic fractions with an antibody to human cytochrome $\mathrm{c}$ after $24 \mathrm{~h} \mathrm{LpqH}$ apoptosis. (b) To determine the mitochondrial membrane damage, we analyzed the mitochondrial membrane potential $(\Delta \Psi \mathrm{m})$ by flow cytometry with DiOC6 in cells induced to apoptosis for $24 \mathrm{~h} ; 27.51 \%$ loss in DiOC6 staining is observed.

are unknown; acyl groups in the lipoprotein are likely candidates, as suggested by studies with artificial bacterial lipoprotein motifs [36]. When TLR2 activated by LpqH will behave as a cell death receptor, as shown in this study, and when it will mediate proinflammatory signals remain as intriguing as yet unanswered questions.

An interesting finding of this study was the apparent cooperation found between extrinsic and intrinsic pathways to provoke $\mathrm{MO}$ apoptosis. Indeed, activation of caspase 9 and cytochrome $c$ released from mitochondria into the cytosol were demonstrated. When a given apoptotic stimulus induces outer mitochondrial membrane (OMM) permeability, cytochrome $\mathrm{c}$ is released from the mitochondria to the cytosol where it mediates apoptosome formation; this macromolecular complex results from the interaction of APAF-1, ATP, and procaspase 9, which is cleaved into its activated form. In turn, active caspase 9 cleaves and activates procaspase 3 , thereby triggering the executioner phase of caspase-dependent apoptosis [29]. In addition, as shown by flow cytometry using the lipophilic fluorochrome DiOC6 a reduction of the mitochondrial transmembrane potential was found; this change indicates permeabilization of the inner membrane, an apoptosis feature less frequent than OMM permeabilization but frequently associated with cytochrome c release [37]. The mechanism interconnecting the extrinsic pathway with the mitochondrial pathway in apoptosis induction requires further study. It has been described that caspase 8 might cleave Bid (BH3-interacting domain death agonist), a proapoptotic Bcl2 (B-cell lymphoma 2) family member; then truncated Bid localizes to the OMM where it promotes Bax (Bcl-2-associated X protein) activation, resulting in release into the cytosol of proapoptotic or antiapoptotic molecules from the mitochondria [38].
The above findings featured the participation of the mitochondria in a caspase-dependent mechanism that trigger $\mathrm{MO}$ death after $\mathrm{LpqH}$ exposure. Since it is well recognized that mitochondria can also release factors involved in caspase-independent cell death [37], we considered this possible. This was also entertained by the limited effect of a pancaspase inhibitor to avoid apoptosis in LpqHchallenged cells. Among the proapoptotic molecules released with OMM permeability is AIF, which has been shown to be frequently involved in caspase-independent apoptosis [39]. AIF is a mitochondrial flavoprotein with a twofold function, in the mitochondria it participates in oxidative phosphorylation, a life function, and, when out of the mitochondria, it provokes cell death [39]. After an apoptotic stimulus, AIF can be cleaved by calpains or cathepsins yielding a truncated $57-\mathrm{kDa}$ form which, once released in the cytosol, relocates to the nucleus to promote chromatinolysis and programmed cell death [33]. In this study, in cells treated with LpqH, AIF was seen by immunoblot in the nuclei and to a lesser extent in the cytosol. In both locations, two bands were detected, one of $57 \mathrm{kDa}$, possibly corresponding to truncated AIF. In addition, by epifluorescence and confocal microscopy, translocation of AIF to the nuclei of most cells was seen at 1 and $24 \mathrm{~h}$. As far as the mechanisms involved in AIF release, it has been shown that overexpression of PARP-1 generates PAR polymers which colocalize with the mitochondria where they induce liberation of AIF to the cytosol with subsequent translocation to cell nuclei [40]. Another factor that may connect caspase-dependent and caspase-independent pathways is caspase 3, which might cleave nuclear PARP-1 [41].

AIF has focused much attention not only as a model of cell death, but also for its role in pathological conditions. It 


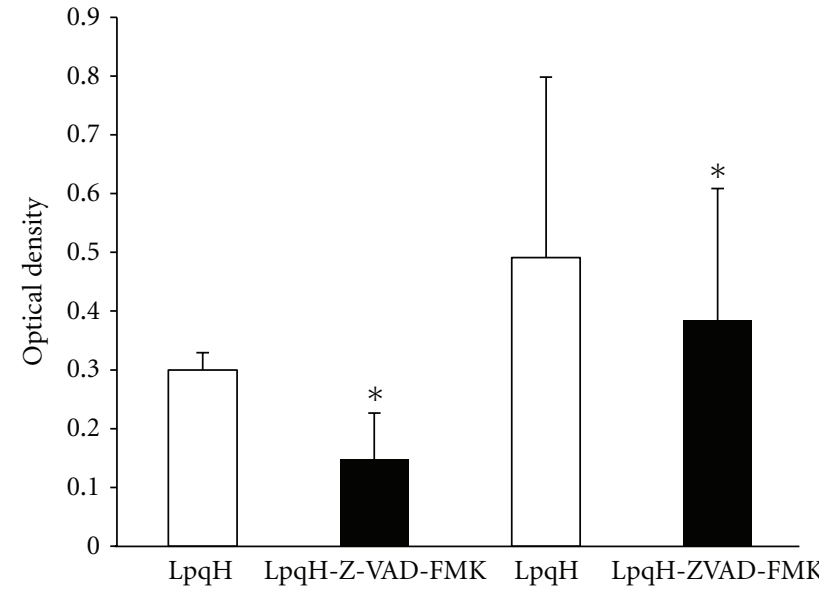

(a)

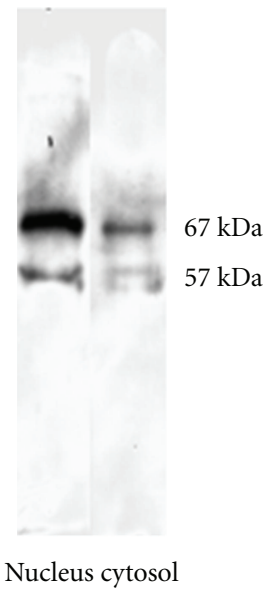

(b)

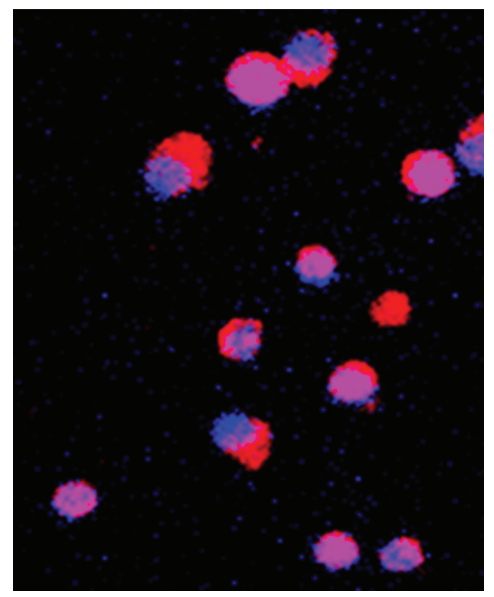

(c)

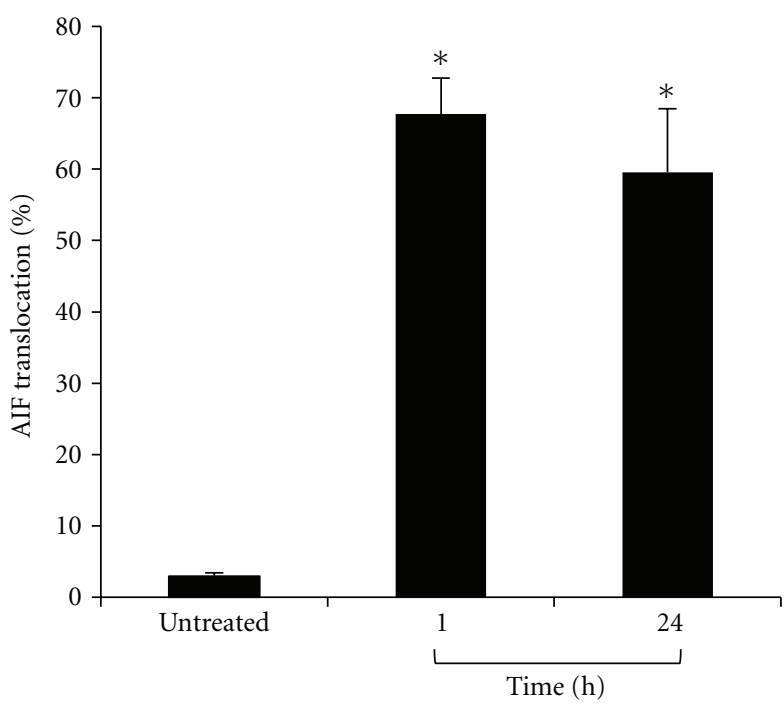

(d)

Figure 6: Caspase-independent mechanisms with AIF relocation are involved in LpqH-induced MO. (a) MOs were preincubated with the pancasphae inhibitor Z-VAD-FMK for $30 \mathrm{~min}$ and thereafter apoptosis was induced with $5 \mu \mathrm{g}$ LpqH for 1 and $24 \mathrm{~h}$; apoptosis was measured by a nucleosome ELISA kit. At $1 \mathrm{~h}$ apoptosis (left) inhibition was of $49.08 \%$ and at $24 \mathrm{~h}$ of $19.41 \%$ (right). Data from four independent experiments are expressed as mean \pm SE of the optical density found; ${ }^{*} P<0.05$. (b) Cells, untreated or treated with LpqH for $24 \mathrm{~h}$, were subjected to subcellular fractionation and immunoblot with a mAb to human AIF using cytosolic and nuclear fractions. (c) For immunofluorescence, after 1 and $24 \mathrm{~h}$ apoptosis induction, MOs were incubated with a mAb to human AIF labeled with CY5 (red fluorescence); nuclei were labeled with DAPI (blue fluorescence). By confocal microscopy, photographs were taken at the midsection of at least 100 cells per condition; photographs were analyzed and merged using the National Institutes of Health ImageJ software (Bethesda, MD, USA). AIF is seen in nuclei as magenta fluorescence frequently massive resulting from the colocalization of CY5 and DAPI; $\times 40$, original magnification. (d) Epifluorescence was used to estimate the percentage of cells showing AIF nuclear translocation at 1 and $24 \mathrm{~h}$; at least 500 cells randomly chosen were photographed and analyzed with Image J; ${ }^{*} P<0.05$.

participates in the death of cancer cells treated with cytotoxic drugs and in various neuropathological processes [42]. Cell death with the participation of AIF has been reported in infectious processes including viral infections such as HIV, [43], rabies [44], and coronavirus [45]. In some bacterial infections, AIF triggers the death of infected cells, including Helicobacter pylori [46], pneumococcus [47], and Coxiella burnetii infections [48]. Regarding pathogenic mycobacteria, AIF-induced MO death has been reported to occur in THP1 monocytes and bovine MO infected in vitro with M. bovis
$[49,50]$. To these observations, it should be added the data herein presented showing that AIF can participate in the death of human MO treated with $\mathrm{LpqH}$, a cell wall, $19 \mathrm{kDa}$ lipoprotein of Mtb.

\section{Conclusion}

Our study documents the high capacity and versatility of a Mtb lipoprotein to assure the death of human monocytederived macrophages. It also shows the high complexity 
of the cell death process and how extrinsic and intrinsic pathways of apoptosis cooperate. The most interesting and previously unreported observation was the participation of the mitochondrial apoptosis factor (AIF) in the macrophage death triggered by a Mtb lipoprotein. It follows to study the molecular mechanisms and the significance of the cooperation between death-receptor and mitochondrial mediated apoptosis.

\section{Acknowledgments}

This work was supported by Grant 41588-M and Student grant (Registro 195122) from the Consejo Nacional de Ciencia y Tecnologia in Mexico. A monoclonal antibody to LpqH was kindly donated by the National Institutes of Health Tuberculosis Research Materials, Colorado State University Contract NO1-AI-40091 (Fort Collins, CO, USA). The authors thank Tzipe Govezensky for statistical analysis and Miguel Tapia for confocal microscope studies. They are indebted to the Instituto Nacional de Rehabilitacion for the donation of blood buffy coats.

\section{References}

[1] J. Keane, H. G. Remold, and H. Kornfeld, "Virulent Mycobacterium tuberculosis strains evade apoptosis of infected alveolar macrophages," Journal of Immunology, vol. 164, no. 4, pp. 2016-2020, 2000.

[2] A. Spira, J. D. Carroll, G. Liu et al., "Apoptosis genes in human alveolar macrophages infected with virulent or attenuated Mycobacterium tuberculosis: a pivotal role for tumor necrosis factor," American Journal of Respiratory Cell and Molecular Biology, vol. 29, no. 5, pp. 545-551, 2003.

[3] J. Maertzdorf, D. Repsilber, S. K. Parida et al., "Human gene expression profiles of susceptibility and resistance in tuberculosis," Genes and Immunity, vol. 12, no. 1, pp. 15-22, 2011.

[4] K. Velmurugan, B. Chen, J. L. Miller et al., "Mycobacterium tuberculosis nuoG is a virulence gene that inhibits apoptosis of infected host cells," PLoS Pathogens, vol. 3, no. 7, article e110, 2007.

[5] M. Oddo, T. Renno, A. Attinger, T. Bakker, H. R. MacDonald, and P. R. A. Meylan, "Fas ligand-induced apoptosis of infected human macrophages reduces the viability of intracellular Mycobacterium tuberculosis," Journal of Immunology, vol. 160, no. 11 , pp. 5448-5454, 1998.

[6] A. Molloy, P. Laochumroonvorapong, and G. Kaplan, "Apoptosis, but not necrosis, of infected monocytes is coupled with killing of intracellular bacillus Calmette-Guerin," Journal of Experimental Medicine, vol. 180, no. 4, pp. 1499-1509, 1994.

[7] S. M. Behar, C. J. Martin, M. G. Booty et al., "Apoptosis is an innate defense function of macrophages against Mycobacterium tuberculosis," Mucosal Immunology, vol. 4, no. 3, pp. 279-287, 2011.

[8] F. Winau, G. Hegasy, S. H. E. Kaufmann, and U. E. Schaible, "No life without death-apoptosis as prerequisite for $\mathrm{T}$ cell activation," Apoptosis, vol. 10, no. 4, pp. 707-715, 2005.

[9] J. Hinchey, S. Lee, B. Y. Jeon et al., "Enhanced priming of adaptive immunity by a proapoptotic mutant of Mycobacterium tuberculosis," Journal of Clinical Investigation, vol. 117, no. 8, pp. 2279-2288, 2007.
[10] J. Keane, M. K. Balcewicz-Sablinska, H. G. Remold et al., "Infection by Mycobacterium tuberculosis promotes human alveolar macrophage apoptosis," Infection and Immunity, vol. 65, no. 1, pp. 298-304, 1997.

[11] S. C. Derrick and S. L. Morris, "The ESAT6 protein of Mycobacterium tuberculosis induces apoptosis of macrophages by activating caspase expression," Cellular Microbiology, vol. 9, no. 6, pp. 1547-1555, 2007.

[12] M. Chen, H. Gan, and H. G. Remold, "A mechanism of virulence: virulent Mycobacterium tuberculosis strain H37Rv, but not attenuated H37Ra, causes significant mitochondrial inner membrane disruption in macrophages leading to necrosis," Journal of Immunology, vol. 176, no. 6, pp. 3707-3716, 2006.

[13] L. Duan, H. Gan, D. E. Golan, and H. G. Remold, "Critical role of mitochondrial damage in determining outcome of macrophage infection with Mycobacterium tuberculosis," Journal of Immunology, vol. 169, no. 9, pp. 5181-5187, 2002.

[14] H. H. Choi, D. M. Shin, G. Kang et al., "Endoplasmic reticulum stress response is involved in Mycobacterium tuberculosis protein ESAT-6-mediated apoptosis," FEBS Letters, vol. 584, no. 11, pp. 2445-2454, 2010.

[15] J. Lee, H. G. Remold, M. H. Ieong, and H. Kornfeld, "Macrophage apoptosis in response to high intracellular burden of Mycobacterium tuberculosis is mediated by a novel caspase-independent pathway," Journal of Immunology, vol. 176, no. 7, pp. 4267-4274, 2006.

[16] A. Ciaramella, A. Martino, R. Cicconi, V. Colizzi, and M. Fraziano, "Mycobacterial 19-kDa lipoprotein mediates Mycobacterium tuberculosis-induced apoptosis in monocytes/macrophages at early stages of infection," Cell Death and Differentiation, vol. 7, no. 12, pp. 1270-1272, 2000.

[17] M. López, L. M. Sly, Y. Luu, D. Young, H. Cooper, and N. E. Reiner, "The 19-kDa Mycobacterium tuberculosis protein induces macrophage apoptosis through toll-like receptor-2," Journal of Immunology, vol. 170, no. 5, pp. 2409-2416, 2003.

[18] S. Basu, S. K. Pathak, A. Banerjee et al., "Execution of macrophage apoptosis by PE_PGRS33 of Mycobacterium tuberculosis is mediated by toll-like receptor 2-dependent release of tumor necrosis factor- $\alpha$," Journal of Biological Chemistry, vol. 282, no. 2, pp. 1039-1050, 2007.

[19] A. Sanchez, P. Espinosa, M. A. Esparza, M. Colon, G. Bernal, and R. Mancilla, "Mycobacterium tuberculosis 38$\mathrm{kDa}$ lipoprotein is apoptogenic for human monocyte-derived macrophages," Scandinavian Journal of Immunology, vol. 69, no. 1, pp. 20-28, 2009.

[20] J. L. Herrmann, P. O'Gaora, A. Gallagher, J. E. R. Thole, and D. B. Young, "Bacterial glycoproteins: a link between glycosylation and proteolytic cleavage of a $19 \mathrm{kDa}$ antigen from Mycobacterium tuberculosis," EMBO Journal, vol. 15, no. 14, pp. 3547-3554, 1996.

[21] H. Diaz-Silvestre, P. Espinosa-Cueto, A. Sanchez-Gonzalez et al., "The 19-kDa antigen of Mycobacterium tuberculosis is a major adhesin that binds the mannose receptor of THP-1 monocytic cells and promotes phagocytosis of mycobacteria," Microbial Pathogenesis, vol. 39, no. 3, pp. 97-107, 2005.

[22] E. H. Noss, R. K. Pai, T. J. Sellati et al., "Toll-like receptor 2dependent inhibition of macrophage class II MHC expression and antigen processing by $19-\mathrm{kDa}$ lipoprotein of Mycobacterium tuberculosis," Journal of Immunology, vol. 167, no. 2, pp. 910-918, 2001.

[23] S. A. Susin, N. Zamzami, M. Castedo et al., "The central executioner of apoptosis: multiple connections between protease activation and mitochondria in Fas/APO-1/CD95- 
and ceramide-induced apoptosis," Journal of Experimental Medicine, vol. 186, no. 1, pp. 25-37, 1997.

[24] A. O. Aliprantis, R. B. Yang, D. S. Weiss, P. Godowski, and A. Zychlinsky, "The apoptotic signaling pathway activated by Toll-like receptor-2," EMBO Journal, vol. 19, no. 13, pp. 33253336, 2000.

[25] R. Haase, C. J. Kirschning, A. Sing et al., "A dominant role of toll-like receptor 4 in the signaling of apoptosis in bacteriafaced macrophages," Journal of Immunology, vol. 171, no. 8, pp. 4294-4303, 2003.

[26] N. Kayagaki, A. Kawasaki, T. Ebata et al., "Metalloproteinasemediated release of human Fas ligand," Journal of Experimental Medicine, vol. 182, no. 6, pp. 1777-1783, 1995.

[27] H. Wajant, K. Pfizenmaier, and P. Scheurich, "Tumor necrosis factor signaling," Cell Death and Differentiation, vol. 10, no. 1, pp. 45-65, 2003.

[28] M. Fotin-Mleczek, F. Henkler, D. Samel et al., "Apoptotic crosstalk of TNF receptors: TNF-R2-induces depletion of TRAF2 and IAP proteins and accelerates TNF-R1-dependent activation of caspase-8," Journal of Cell Science, vol. 115, no. 13, pp. 2757-2770, 2002.

[29] P. Li, D. Nijhawan, I. Budihardjo et al., "Cytochrome c and dATP-dependent formation of Apaf-1/caspase- 9 complex initiates an apoptotic protease cascade," Cell, vol. 91, no. 4, pp. 479-489, 1997.

[30] P. X. Petit, H. Lecoeur, E. Zorn, C. Dauguet, B. Mignotte, and M. L. Gougeon, "Alterations in mitochondrial structure and function are early events of dexamethasone-induced thymocyte apoptosis," Journal of Cell Biology, vol. 130, no. 1, pp. 157-167, 1995.

[31] B. Dallaporta, P. Marchetti, M. A. De Pablo et al., "Plasma membrane potential in thymocyte apoptosis," Journal of Immunology, vol. 162, no. 11, pp. 6534-6542, 1999.

[32] E. Hangen, K. Blomgren, P. Bénit, G. Kroemer, and N. Modjtahedi, "Life with or without AIF," Trends in Biochemical Sciences, vol. 35, no. 5, pp. 278-287, 2010.

[33] S. A. Susin, H. K. Lorenzo, N. Zamzami et al., "Molecular characterization of mitochodrial apoptosis-inducing factor," Nature, vol. 397, no. 6718, pp. 441-446, 1999.

[34] P. Schneider, N. Holler, J. L. Bodmer et al., "Conversion of membrane-bound Fas(CD95) ligand to its soluble form is associated with downregulation of its proapoptotic activity and loss of liver toxicity," Journal of Experimental Medicine, vol. 187, no. 8, pp. 1205-1213, 1998.

[35] T. Mustafa, S. Phyu, R. Nilsen, G. Bjune, and R. Jonsson, "Increased expression of Fas ligand on Mycobacterium tuberculosis infected macrophages: a potential novel mechanism of immune evasion by Mycobacterium tuberculosis?" Inflammation, vol. 23, no. 6, pp. 507-521, 1999.

[36] A. O. Aliprantis, R. B. Yang, M. R. Mark et al., "Cell activation and apoptosis by bacterial lipoproteins through Toll- like receptor-2," Science, vol. 285, no. 5428, pp. 736-739, 1999.

[37] K. M. Heiskanen, M. B. Bhat, H. W. Wang, J. Ma, and A. L. Nieminen, "Mitochondrial depolarization accompanies cytochrome c release during apoptosis in PC6 cells," Journal of Biological Chemistry, vol. 274, no. 9, pp. 5654-5658, 1999.

[38] H. Li, H. Zhu, C. J. Xu, and J. Yuan, "Cleavage of BID by caspase 8 mediates the mitochondrial damage in the Fas pathway of apoptosis," Cell, vol. 94, no. 4, pp. 491-501, 1998.

[39] S. P. Cregan, V. L. Dawson, and R. S. Slack, "Role of AIF in caspase-dependent and caspase-independent cell death," Oncogene, vol. 23, no. 16, pp. 2785-2796, 2004.
[40] N. Joza, S. A. Susin, E. Daugas et al., "Essential role of the mitochondrial apoptosis-inducing factor in programmed cell death," Nature, vol. 410, no. 6828, pp. 549-554, 2001.

[41] S. W. Yu, H. Wang, M. F. Poitras et al., "Mediation of poty(ADP-ribose) polymerase-1-dependent cell death by apoptosis-inducing factor," Science, vol. 297, no. 5579, pp. 259-263, 2002.

[42] H. K. Lorenzo and S. A. Susin, "Therapeutic potential of AIFmediated caspase-independent programmed cell death," Drug Resistance Updates, vol. 10, no. 6, pp. 235-255, 2007.

[43] K. F. Ferri, E. Jacotot, J. Blanco et al., "Apoptosis control in syncytia induced by the HIV type 1-envelope glycoprotein complex: role of mitochondria and caspases," Journal of Experimental Medicine, vol. 192, no. 8, pp. 1081-1092, 2000.

[44] L. Sarmento, T. Tseggai, V. Dhingra, and Z. F. Fu, "Rabies virus-induced apoptosis involves caspase-dependent and caspase-independent pathways," Virus Research, vol. 121, no. 2, pp. 144-151, 2006.

[45] D. J. Favreau, M. Meessen-Pinard, M. Desforges, and P. J. Talbot, "Human coronavirus-induced neuronal programmed cell death is cyclophilin d dependent and potentially caspase dispensable," Journal of Virology, vol. 86, no. 1, pp. 81-93, 2012.

[46] H. Ashktorab, R. H. Dashwood, M. M. Dashwood et al., "H. pylori-induced apoptosis in human gastric cancer cells mediated via the release of apoptosis-inducing factor from mitochondria," Helicobacter, vol. 13, no. 6, pp. 506-517, 2008.

[47] J. S. Braun, R. Novak, P. J. Murray et al., "Apoptosis-inducing factor mediates microglial and neuronal apoptosis caused by pneumococcus," Journal of Infectious Diseases, vol. 184, no. 10, pp. 1300-1309, 2001.

[48] Y. Zhang, G. Zhang, L. R. Hendrix, V. L. Tesh, and J. E. Samuel, "Coxiella burnetii induces apoptosis during early stage infection via a caspase-independent pathway in human monocytic THP-1 cells," PLoS ONE, vol. 7, no. 1, Article ID e30841, 2012.

[49] J. Zhang, B. Sun, Y. Huang et al., "IFN- $\gamma$ promotes THP- 1 cell apoptosis during early infection with Mycobacterium bovis by activating different apoptotic signaling," FEMS Immunology and Medical Microbiology, vol. 60, no. 3, pp. 191-198, 2010.

[50] X. Vega-Manriquez, Y. López-Vidal, J. Moran, L. G. Adams, and J. A. Gutiérrez-Pabello, "Apoptosis-inducing factor participation in bovine macrophage Mycobacterium bovis-induced caspase-independent cell death," Infection and Immunity, vol. 75, no. 3, pp. 1223-1228, 2007. 


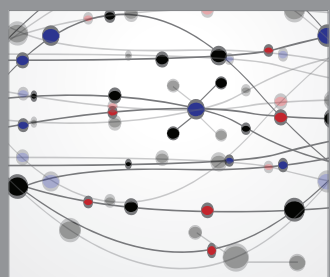

The Scientific World Journal
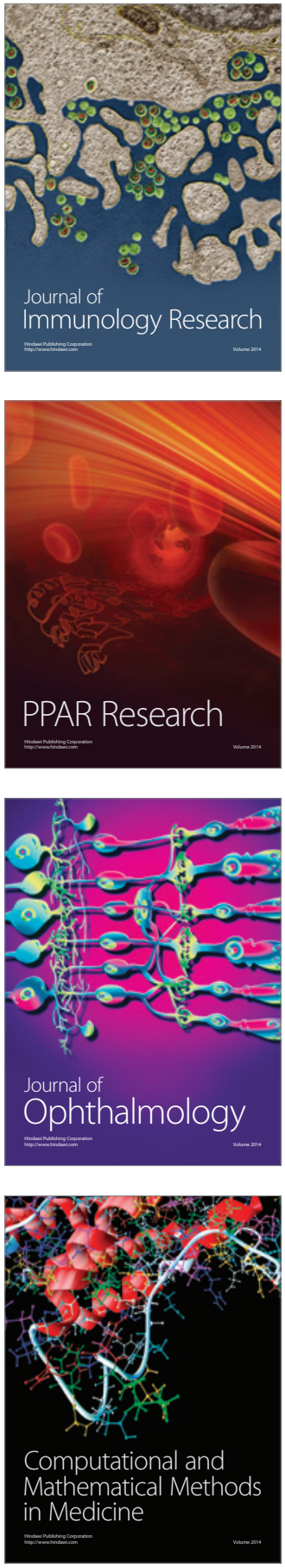



Gastroenterology

Research and Practice
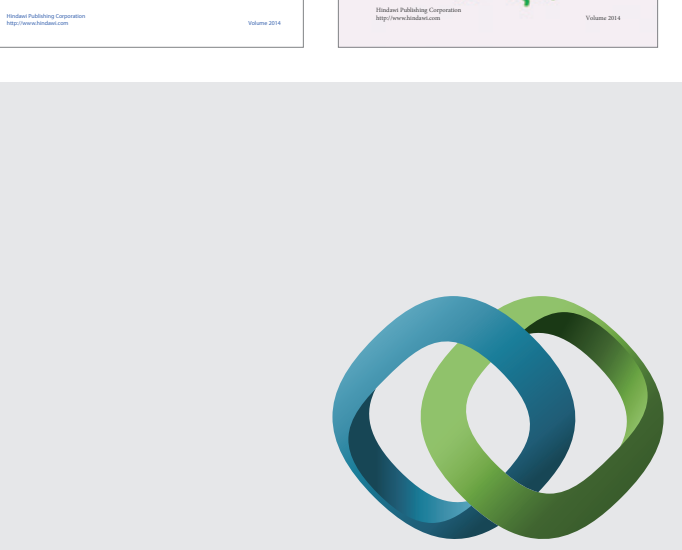

\section{Hindawi}

Submit your manuscripts at

http://www.hindawi.com
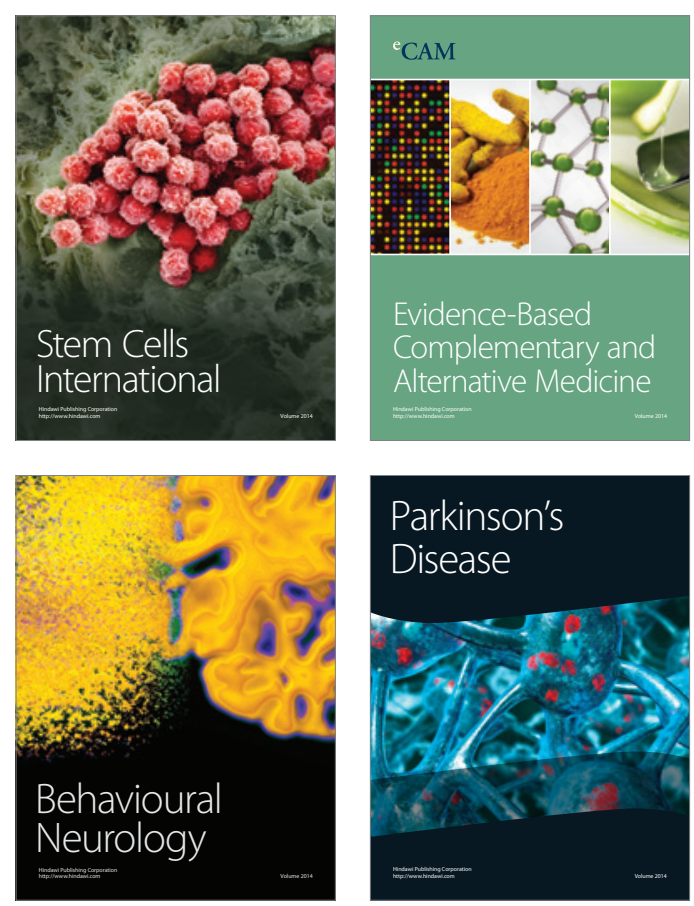

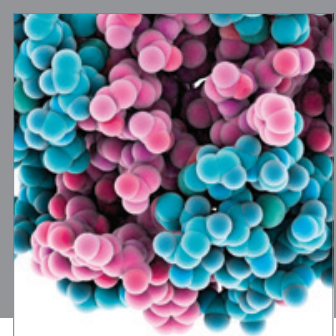

Journal of
Diabetes Research

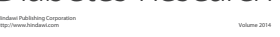

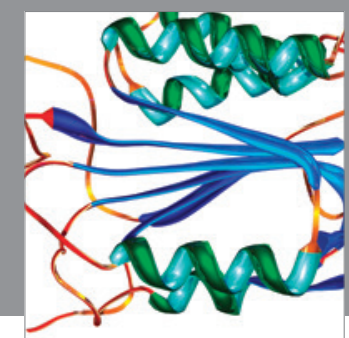

Disease Markers
